\title{
ФУНКЦИОНАЛЬНАЯ СЕМАНТИКА
}

Удк: 81'374

DOI: $10.22363 / 2313-2299-2018-9-3-612-624$

\section{«ЛИНГВИСТИЧЕСКАЯ ЭНЦИКЛОПЕДИЯ"- НЕИЗВЕСТНЫЙ ЛЕКСИКОГРАФИЧЕСКИЙ ПРОЕКТ 1930-х ГОДОВ}

\author{
О.В. Никитин \\ Московский государственный областной университет \\ ул. Веры Волочиной, 24, г. Мытищии, Московская область, 141014
}

В статье анализируется проект «Лингвистической энциклопедии» 1930-х гг. Концепция издания была разработана известным историком и теоретиком языкознания Р.О. Шор в виде развернутой докладной записки в Научно-исследовательский институт языкознания. Идея создания «Лингвистической энциклопедии» включена в контекст научных дискуссий, общественно-политической ситуации 1920-1930-х гг. и тех задач, которые возникли перед советскими учеными по языковому строительству, методике изучения языков южных регионов страны, разработке общих вопросов теории и методологии лингвистики. Автор статьи подчеркивает очевидный идеологический характер многих утверждений, свидетельствующий о борьбе разных направлений в языковедческой науке и нарастающем давлении марризма. Впервые представляется и комментируется подлинный текст этого проекта из коллекции фондов Архива РАН. Работа решает малоизвестные проблемы в истории языкознания и способствует объективному пониманию сложных процессов социологии лингвистической науки в период ее адаптации к новым условиям работы (дискуссии, притеснение традиционной компаративистики, борьба с «поливановщиной» и т.д.).

Ключевые слова: история и теория языкознания, лингвистическая дискуссия, марризм, языковая ситуация, лексикография

История отечественной науки первой половины XX века, особенно времени так называемого языкового строительства и перекройки гуманитарного образования в 1920-1930-х гг., изучена еще недостаточно хорошо. Многие лингвистические сюжеты тех лет до сих пор неизвестны филологической аудитории, хотя основные тенденции в науке уже подробно описаны, а архивные публикации последних десятилетий внесли существенный вклад в копилку объективных знаний $[1 ; 4 ; 13-15 ; 17]$. Это связано прежде всего с фрагментарностью разработки отдельных отраслей языкознания. Несмотря на то, что трагические годы славистики, дискуссии 1940-1950-х гг. уже не раз являлись предметом исследования, были вскрыты и обнародованы новые факты, переосмыслены теоретические положения классиков советской лингвистики, даны критические оценки многим забытым датам и именам, целостной картины развития филологии в эти годы мы 
не имеем. Тем не менее опубликованные документы позволяют нам опираться на вполне надежные источники и последовательно строить историю русского языкознания XX века без штампов и очевидных лакун.

Какие же события в культурном пространстве общества так или иначе повлияли на формирование лингвистического портрета эпохи первых десятилетий советской власти? Прежде всего надо сказать о том, как изменился системный принцип высшей школы, которая все более приобретала прикладной характер и вплеталась в маховик социалистического строительства. Для этого создавались новые учебники и энциклопедии. Еще в 1920-х гг. взрослые граждане в глубинке слабо владели элементарными правилами грамматики. Необходимо было заниматься просветительством: обучать не только детей, но и старшее поколение, создавать алфавиты для бесписьменных народов СССР и т.д. В эту работу включились ведущие лингвисты и методисты того времени Д.Н. Ушаков, М.Н. Петерсон, А.М. Пешковский, Н.Н. Дурново, Е.Д. Поливанов, Н.Ф. Яковлев, А.М. Сухотин, Р.О. Шор. Их опыт не являлся упрощенчеством. В силу сложившихся обстоятельств они вынуждены были писать учебники для рабфаков, создавать новые методики для обучения полуобразованных рабочих и крестьян, ездить в экспедиции, живой говор превращать в письменность. Формальное языкознание как наука в большей степени диахроническая способствовала развитию и утверждению конкретных лингвистических задач того времени.

Словари и энциклопедии принуждены были выполнять не только педагогическую, но и в известной степени идеологическую задачу. Именно тогда, в начале 1920-х гг., родилась идея создания «Словаря современного русского литературного языка» по типу Лярусса [8; 9; 12], в котором определенное место в качестве источников занимали труды деятелей революционного движения наряду с поэтами и писателями Серебряного века. В 1924 г. Н.Н. Дурново опубликовал первый в истории отечественного языкознания «Грамматический словарь (грамматические и лингвистические термины)» (см: [5]). В нем проводилась линия Московской лингвистической школы. В 1925 г. вышел двухтомник «Литературной энциклопедии», которая поместила в том числе и статьи лингвистов формального направления, например, А.М. Пешковского (см.: [11]). Но все же к началу 1930-х гг. у нас не было сколько-нибудь подробной специальной энциклопедии, посвященной теории языкознания и общим проблемам лингвистики (не только российской, но и иностранной). Правда, отдельные статьи выходили в «Большой советской энциклопедии», и все еще издавался «Энциклопедический словарь» братьев Гранат. Но это были почти не замеченные никем краткие заметки, не влиявшие на становление новой науки о языке.

Несколько особняком здесь стоял Е.Д. Поливанов, дерзнувший вопреки нараставшему марровскому влиянию показать свое видение языкового процесса и подготовить оригинальный труд в духе лучших традиций лингвистической типологии и компаративистики. Но его словарь так и остался неизданным и пролежал в архиве десятилетия [16]. Как авторский лексикон лингвистических терминов его уникальный эксперимент, безусловно, представляет исключительное явление в нашей филологической науке, но никакого влияния на развитие языкознания 1930-х гг. он не имел. 
В целях систематизации знаний и утверждения новой политики в этой отрасли необходима была разработка целого направления - лексикографии, которое бы, с одной стороны, приобщало читательские массы к слову, с другой воспитывало их в новых историко-культурных условиях. Происходила «борьба идей и идеологий» в науке [13]. Еще в конце 1920-х гг. началась работа по составлению первого нормативного толкового словаря советской эпохи - «Ушаковского», как позднее его неофициально назовут. Он несколько лет, в самые непростые годы суда над славистикой, находился под огнем марровской критики (см. описание дискуссии: [10;12]). А в начале 1930-х годов была предпринята попытка уже с более «прогрессивных» коммунистических позиций составить лингвистическую энциклопедию, которая выполняла бы функцию форпоста в борьбе с «антимарксистскими формалистическими и идеалистическими воззрениями на язык» [ЛЭ, л. 3].

Эта идея принадлежала известному филологу Розалии Осиповне Шор (18941939). Она начинала как компаративист, отлично знала санскрит и древнеиндийскую литературу, занималась переводами, публиковала труды по истории западноевропейской литературы. В 1920-е гг. вела активную преподавательскую и научную деятельность в Лингвистической секции Института языка и литературы РАНИОН, Институте народов Востока, Государственной академии художественных наук (ГАХН). В 1930-е гг. она была действительным членом Научноисследовательского института языкознания (НИЯЗ), заведовала кафедрой общего языкознания Московского института философии, литературы и истории (МИФЛИ), занималась большой общественной работой (см. подробнее: [2; 3]).

Собрание документов и писем Р.О. Шор, находящееся в Архиве РАН, показало, насколько разнообразны и глубоки были ее филологические устремления. Среди найденных нами материалов оказалась и докладная записка «Об организации „Лингвистической энциклопедии“» — интереснейший факт не только с точки зрения лексикографической теории и практики, но крупное событие в гуманитарной науке. Оно обнажило остро стоявшие перед нашими учеными проблемы научной теории и практики 1930-х гг.

Вверху имеющейся в нашем распоряжении машинописи (12 листов узких столбцов) перед заглавием напечатано: «Составлено Р. Шор по заданию руководства „НИЯз“». И ниже титул: «Об организации издания „Лингвистической энциклопедии“ (докладная записка)» [ЛЭ, л. 1].

Она начиналась с общих положений о необходимости пропаганды достижений марксистской науки, которая уже приняла массовый агитационный характер в энциклопедиях общего и специального назначения:

«Переход от первой пятилетки ко второй, мощное развертывание социалистического строительства, рост кадров научных работников-марксистов и выразившееся в дискуссиях последних лет вскрытие и очищение советской науки на всех ее участках от ряда идеалистических и механических ошибок делает возможным широкую популяризацию достижений марксистской науки не только в справочных изданиях сводного типа /БСЭ, МСЭ/, но и в специальных справочных изданиях по единой дисциплине или по кругу близких дисциплин» [ЛЭ, л. 1]. 
В то же время, сетовал автор, «отсутствует энциклопедия по вопросам языкознания» [Там же]. «Между тем, — продолжала далее Р.О. Шор, - положение на этом участке идеологического фронта таково, что организация подобного издания кадрами марксистов-лингвистов является настолько необходимой и неотложнейшей задачей ближайшего времени» [Там же].

Затем в кратком обзоре наиболее важных, по мнению ученого, проблем современной (1920-1930-е гг.) лингвистики она обсуждала ключевые вопросы общественной и культурной панорамы жизни, имевшие отношение прежде всего к языковому строительству. Р.О. Шор ссылалась на «ленинскую национальную политику в СССР», которая привела, как она полагала, к расцвету «национальных по форме и социалистических по содержанию» [Там же, лл. 1-2] культур. В этих условиях необходимо было усилить работу по обучению местных народов на родном языке и таким образом укрепить идеологические позиции советской власти. Однако и здесь нашлись определенные проблемы. Р.О. Шор утверждала:

«...на этом участке социалистического строительства можно констатировать досадное отставание лингвистической теории от языковой политики [и] практики пролетариата и его авангарда — партии: наличие в языковедных теоретических и практических выступлениях уклонов от генеральной линии партии, как в сторону великодержавного шовинизма, так и в сторону местного национализма, использование в национальных учебниках порочных построений старых /миссионерских/ лингвистических школ, обслуживавших прямые интересы царской колонизаторской политики и великорусской ассимиляции, малая осведомленность широких читательских масс в вопросах языкового строительства - все это настойчиво сигнализирует необходимость продвижения в широкие массы читателей правильных (курсив наш. - O.Н.) сведений о языках народов СССР, <..> об их взаимодействии (так в тексте. - O.H.), - словом, тех сведений, которые могут содействовать развертыванию языкового строительства в направлении, указанном генеральной линией политики пролетариата» [Там же, лл. 2-3].

Но не только в этом видела Р.О. Шор пробелы в стратегии лингвистического образования. Многие идеи старой школы, усвоенные прежними поколениями ученых, продолжали распространяться и в массовом порядке в вузовских и школьных учебниках, что не отражало «марксистско-ленинской методики языка». В связи с этим она ставила перед лингвистами задачу продвижения новых форм языкового строительства. Вот как Р.О. Шор об этом писала:

«Между тем и на этом участке идеологического фронта мы не можем еще констатировать удовлетворительного состояния. В программах, учебниках и методических пособиях по языку слишком часто еще проводятся антимарксистские формалистические и идеалистические воззрения на язык, особенно сильно это неблагополучие выявляется на наиболее ответственном и центральном участке школьной работы по языку - участке грамматики. И здесь неотложной задачей является создание такого справочника, который дал бы школьному работнику правильные марксистско-ленинские установки на всех участках его работы» [Там же, л. 3]. 
Общественный пафос автора идеи порой выходил и за рамки научной теории вопроса. Р.О. Шор включалась в дискуссию о международной ситуации и в духе своего времени порицала врагов народа. Приведем характерную реплику из первой части проекта «Лингвистической энциклопедии»:

«П[е]речисленными участками социалистического строительства, несмотря на их кардинальную важность, отнюдь не ограничивается область применения языковедных сведений: в условиях современного международного положения усиленной деятельности врагов Советского Союза и социалистического строительства, кануна краха капиталистических государств и роста революционного рабочего движения, интересы интернационального воспитания трудящихся требуют ознакомления их с языковой ситуацией за пределами СССР, с характером языков запада и Востока, в частности, языков „колониальных“, с классовой борьбой в языке и посредством языка» [Там же, лл. 3-4].

Показательно, что Р.О. Шор не осталась в стороне от печально известной акции по дискредитации «буржуазных индоевропеистов» и «формалистов», которая набирала обороты с конца 1920-х — начала 1930-х гг. Здесь необходимо вспомнить дискуссию в НИЯЗ о трудах и научной деятельности А.М. Селищева [7; 14; 15], выпады в адрес А.М. Пешковского [11], травлю Е.Д. Поливанова [3] и другие трагические события того непростого времени. Казалось бы, зачем в таком издании обострять этот вопрос и ввязываться в борьбу на «идеологическом фронте» науки? Может быть, эта позиция отчасти объясняется особенностями ее характера и «женской доли»: она всю жизнь пробивала себе дорогу в мужском окружении, старалась быть на виду, и своими способностями и неистовым трудолюбием завоевывала авторитет, став уже в конце 1920-х гг. признанным в СССР теоретиком языкознания (вспомним отклик на ее книгу «Язык и общество» знаменитого французского лингвиста А. Мейе).

Р.О. Шор была инициатором серии «Языковеды Запада», в которой переиздали «Курс общей лингвистики» Ф. де Соссюра, труды Э. Сепира, Ж. Вандриеса, В. Томсена и А. Мейе (см. подробнее: [2; 3]). И все это было возможно благодаря неутомимой пробивной энергии Р.О. Шор. Она, безусловно, понимала, что заниматься зарубежной (=буржуазной) лингвистикой в середине - второй половине 1930-х гг. чревато большими неприятностями. Все-таки, выпуская сочинения классиков западноевропейской мысли, и в подготовленном проекте «Лингвистической энциклопедии» она тем не менее настаивала на критике «построений буржуазной лингвистики» и теории «миграции частей единого пранарода» [ЛЭ, л. 9]. В общем, ее большие познания все время наталкивались на внутренние духовные споры: она то прорывалась вперед и шла в передовых шеренгах лингвистов, то отступала и повторяла затрепанные лозунги марристов и невольно скрывалась за мощной амбразурой идеологии марксизма-ленинизма.

Следующий фрагмент ее «докладной записки» как раз свидетельствует о противоречивости взглядов ученого и в целом неустойчивости общественной позиции в языкознании, где начиналась «эпоха разоблачений»:

«В условиях обостренной классовой борьбы и необходимости обостренной классовой бдительности весьма важное значение приобретает борьба со всеми 
попытками маскировки классово-враждебных разоружающих пролетариат идеологий, имевшими место и на языковедном участке /поливановщина, троцкизм, меньшевиствующий идеализм/. Как разоблачение классово-враждебных идеологий на лингвистическом участке, так и развернутое систематическое изложение марксистско-ленинской науки о языке предопределена ленинским разрешением вопроса о наследстве в научном строительстве пролетариата /,Речь о задачах комсомола“ и др./. Поэтому „Лингвистическая энциклопедия“ должна дать всю сумму знаний, добытых человечеством на участке языкознания, дать характеристику важнейших деятелей этой науки, но дать ее не в духе буржуазного об[ъ]ективизма, а в критическом освещении с позиции диалектического материализма, с позицией (так в тексте. - $О$. .. .) ленинской партийности в науке» [Там же, лл. 4-5].

Все сказанное подводило мысль Р.О. Шор к необходимости коренным образом обновить аппарат лингвистической науки и подготовить авторитетное издание, которое применяло бы иные принципы научной работы (отход от «формализма» и традиций Московской лингвистической школы, социологизация языкознания, использование методологии нового учения о языке и т.д.) и соответствовало идеологии времени. Она, конечно же, была отлично знакома с похожими опытами, но отвергала их. Так, «Грамматический словарь» Н.Н. Дурново Р.О. Шор назвала «насквозь формалистическим и идеалистическим» [Там же, л. 5]. Будучи автором ряда статей в «Большой советской энциклопедии», она и в ней усмотрела недостатки:

«Лингвистика в БЭС носит, в особенности в первых 15 томах, преимущественно „беспартийный“, идеологически „нейтральный“ характер, статьи втиснуты в большинстве случаев в форму „академических“ очерков и справок; часто они излишне элементарны, а еще чаще излишне „учены“ и специальны. Вместо единой марксистской, диалектически-материалистической методологической установки читатель находит полный разнобой методов и воззрений. И наконец, скромные размеры, отведенные в БСЭ лингвистике, не дают возможности развернуть этот отдел в заслуживаемой им полноте» [Там же, лл. 5-6].

Досталось и «Литературной энциклопедии» от бойкого пера Р.О. Шор (кстати, она была ее автором и редактором). Она усмотрела в ней принадлежность к старой описательной лингвистике. Значит, и этот труд не подходил под критерии большого современного терминологического словаря. В ее «докладной записке» читаем:

«В предисловии к этой энциклопедии указано, что эстетика и лингвистика, являющиеся для литературоведа вспомогательными дисциплинами, даны лишь в той мере, в какой это нужно для критического восприятия основного литературоведческого материала. Центр внимания сосредоточен на о п и с ан и и яз ы к о в . Большинство описаний носит справочный характер в форме ряда внешних замечаний: географическая распространенность, принадлежность к той или иной группе, количество говоров и наречий, иногда несколько замечаний о грамматике - и все. Но это чаще всего для более или менее отдаленных и небольших языков /абиссинский, афганский и пр./. Только о некоторых дано более обстоятельно /английский язык/» [Там же, л. 6]. 
Кроме того, у Р.О. Шор вызывал опасение и другой факт. Как теоретик языкознания она стремилась создать новую методологию этой науки, отвечавшую бы требованиям социалистической идеологии. Поэтому в своих тезисах она снова балансировала между классической школой, к которой принадлежала в юности, и современной, и выбор делала часто в сторону последней. Думаем, что он давался ей не так просто. Процитируем еще один фрагмент этой заметки Р.О. Шор:

«В методологическом отношении статьи ЛЭ в основном также пестры, как и статьи в БСЭ. Обычно статьи о кавказских и восточных языках написаны преимущественно с точки зрения яфетидологии, а о европейских - преимущественно с точки зрения индоевропеистики. Таким образом[,] наличный справочный материал отнюдь не может заменить той лишь энц<иклопедии $>[$,] появление которой настоятельно диктуется потребностями текущего этапа социалистического строительства» [Там же, лл. 6-7].

После краткого изложения концепции заявленного издания и подведения идеологической платформы Р.О. Шор далее говорила о структуре намеченной книги. Она должна была состоять, по мнению автора, из трех разделов:

«1. Статьи по языковедению и языковому строительству.

2. Статьи по методике языка.

3. Статьи по дисциплинам, тесно соприкасающимся с наукой о языке в деле обслуживания языкового строительства народов СССР, как стенография, полиграфическое дело и т.п.» [Там же, л. 7].

В следующей части Р.О. Шор предлагала схему размещения словарных статей, разделив их на две части: лингвистические и методические работы. Первые включили, как она предполагала, «сведения по отдельным языкам и языковым группам», «статьи об отдельных лингвистах» и «статьи по лингвистической теории и терминологии» [Там же, л. 7]. Показательно, что проблемы истории языка тоже должны были бы освещаться в «Лингвистической энциклопедии», но с учетом «текущего момента». Политизация этой части, ее условность и подчиненность диктатуре Марра очевидна. Вот как видела это в своем издании Р.О. Шор:

«...факты истории языка связываются с данными истории общественных формаций и массовой борьбы - так освещаются изменения строя языка и семантики, история литературного языка как языка господствующего класса, как отражение и орудие классовой борьбы, факт языкового смешения и отношение к языкам национальных меньшинств на территории того же государственного образования, национально-языковая политика господствующего класса /для нацменьшинства — борьба за национальный язык и текущий этап его строительства/» [Там же, лл. 7-8].

Мы не раз встречали на страницах заметки сочетание «языковое строительство», характерное и для других работ тех лет. Но что же в него вкладывала Р.О. Шор? Какие задачи она ставила перед лингвистикой в этом, едва ли не центральном направлении «идеологического фронта» науки? Она пояснила это так:

«...характеристика современного состояния языка границы т.н. местных диалектов и их пережиточныцй (курсив наш. - O.Н.) характер, наличие литера- 
турного и письменного языка, его классовость, борьба классов за литературный язык / для языков СССР...» [Там же, л. 8].

Заметим попутно, что к этому времени была практически свернута деятельность Московской диалектологической комиссии в ее дореформенном состоянии [6], а в 1931 г. ее вовсе ликвидировали. И в изучении диалектов, насколько это было возможно, на первом месте стояли «классовые» задачи.

Интересен в русле развития лингвистики 1920-1930-х гг. такой тезис ученого:

«В перечне литературы предполагается дать краткую характеристику основных направлений существующей по данному языку литературы, вскрывающую их классовую направленность, империалистические и националистические установки и т.П.» [ЛЭ, лл. 8-9].

И снова звучал громкий тезис о «классовости», распределявший кирпичики научного анализа по принципу «свой - чужой»:

«Статьи по истории соответствующего раздела лингвистики /под словами „Угрофиноведение“, „Семитология“, „Индоевропеистика“, „Яфетидология“ и т.п./ должны дать характеристику его основных направлений в прошлом и настоящем, вскрывая их классовую направленность /империалистические, националистические установки/ и под этим углом зрения переоценивая построения буржуазных ученых» [Там же, л. 9].

В энциклопедии планировалось разместить и статьи «об отдельных лингвистах», имевших «существенное значение для развития методологии языкознания» [Там же, л. 9]. Имена их не назывались, но указывалось на то, что необходимо вскрыть их «философские и классовые корни» [Там же, л. 10].

На многих страницах данного проекта отмечалось, что «Лингвистическая энциклопедия» должна «популяризировать достижения марксистско-ленинского этапа развития материалистической лингвистики» [Там же, л. 10]. Это касалось как проблем истории, методологии науки и стратегии ее развития, так и частных задач: правильно с точки зрения марксистской идеологии описать «установочные термины» типа грамматика, где также надо показать «классовую значимость» не только в синхронии, но и в диахронии. Статьи, требующие развернутого объяснения вроде имя, глагол, также, по мнению Р.О. Шор, должны включать «современное разрешение вопроса в системе марксистской лингвистики» [Там же, л. 11]. Особое внимание она предлагала уделять не только критике положений буржуазной лингвистики, но и «первых этапов материалистического языкознания», т.е. яфетической теории [Там же, л. 10], и отмечать ее применение «в соц<иалистическом> строительстве народов СССР» [Там же, л. 11].

Схема статей второй части словаря включала работы «о важнейших методистах» [Там же, л. 11]. Р.О. Шор высказалась «против отделения раздела методики от раздела языковедения в области лингвистической грамматики» [Там же, л. 11]. Эта точка зрения практиковалась, как она писала далее, «в некоторых старых справочных изданиях» [Там же, лл. 11-12] и не могла использоваться в языковом строительстве. Автор полагал, что такая позиция «является лишь одним из случаев отрыва теории от практики, характерного для буржуазного языковедения» [Там же, л. 12]. 
Самая скромная, но важная в концепции задуманного издания часть - статьи по дисциплинам, которые обслуживают языковое строительство народов СССР. К ним Р.О. Шор отнесла термины стенография, полиграфическое производство, шрифт и т.д. [Там же, л. 12].

Проект Р.О. Шор по изданию «Лингвистической энциклопедии» так и не был реализован, а потом, по-видимому, в связи с трагическими обстоятельствами и так называемым «делом славистов» вовсе заброшен - заниматься сложным вопросом, требующим привлечения специалистов разных отраслей языкознания, было небезопасно ученому, стоявшему на грани марксистских взглядов. К тому же Р.О. Шор довольно рано умерла, в 1939 г. И этот оригинальный замысел забыли. Между тем даже в виде достаточно подробной «докладной записки» он ценен как факт истории лингвистики 1930-х гг., свидетельствующий о большом интересе советских ученых к непростым дискуссионным проблемам общего языкознания. «Лингвистическая энциклопедия» показала, что под прикрытием «идеологического строительства» ученые пытались исследовать живые процессы современного языка. И в этом смысле Р.О. Шор выходила за пределы нашей традиционной науки и смотрела далеко вперед, в ее будущее (например, она говорила о статусе международного языка и т.д.).

Р.О. Шор при всех ее «скитаниях» обладала уникальным даром видеть и чувствовать языки как явление культуры, проникать в их строение, творчески подходить к их изучению. Помнится, при разборе архива Р.О. Шор мне попались на глаза многочисленные таблички и карточки с классификациями языков мира, которые старательно выполнила первая женщина-лингвист XX века. Она была не только интересным теоретиком языкознания, но и авторитетным, мы бы сказали, неутомимым практиком, преданным науке до последних дней. Ее научное творчество, как мы полагаем, еще нуждается в осмыслении и открытии, как и многое из того, что осталось после нее в архивах.

Р.О. Шор была необычным явлением в науке 1920-1930-х гг. Единственная видная женщина-идеолог в лингвистике, теоретик, отличный методист и организатор науки, она обладала поистине широчайшими познаниями в разных отраслях филологии, «сочетала женственность с ученостью», как о ней говорили, обладала огромной эрудицией и фантастической работоспособностью [3]. Но смогла завершить далеко не все, что было задумано. Просмотренные нами личные материалы P.О. Шор в Архиве РАН, пока еще не до конца укомплектованные и сформированные в отдельный фонд, дают отличное представление о масштабе этой личности, попавшей под жернова культурных истязаний своего века. Она великолепно знала Ф. де Соссюра, была одним из первых социолингвистов, во многом выступала в роли первопроходца. И тем не менее не устояла в перипетиях сложной биографии науки, склонялась к Н.Я. Марру, по выражению П.С. Кузнецова (см.: [3]). «Она была по природе эклектична, заигрывала с марризмом», - выразился однажды о ней А.А. Реформатский [Там же]. Отчасти эта увлеченность мифом, 
который, наверное, в глубине души ей был не так интересен, оттолкнула ее от настоящей компаративистики и традиций Московской лингвистической школы, в которых она взрастала как ученый - Р.О. Шор все больше работала в стол и внешне старалась не конфликтовать со сторонниками взглядов главы советского языкознания тех лет. Это, как мы увидели, хорошо показано в ее «докладной записке» «Об организации „Лингвистической энциклопедии“»».

Ключевыми словами работы Р.О. Шор, которые задают тон всему проекту «Лингвистической энциклопедии», являются характерные для марровской стилистики того времени сочетания вроде «идеологический фронт», «марксистсколенинское языкознание», «классовая борьба в языке», «разоблачение классововраждебных идеологий на лингвистическом участке» и т.д. В статье не раз фигурировали ссылки на печатные труды и выступления Сталина и недвусмысленно клеймились «троцкисты», в одном ряду с которыми оказался и Е.Д. Поливанов. Подобные реплики и в устной форме, в дискуссиях, и в письменной полемике нередко звучали в то время как лозунги-идеологемы, подчеркивавшие преимущество нового мышления перед старым, «буржуазным». Но все же и в лексикографических состязаниях, пусть и находившихся под давлением трагической истории, мы не могли не заметить и весьма интересные, по сути даже философские проблемы языкознания, которые пыталась решить Р.О. Шор в своей энциклопедии: упорядочение системы лингвистических дисциплин, их терминологии, указание на важность филологического образования в национальных республиках, обсуждение системных вопросов методологии языкознания, оценка состояния и ресурсов лингвистики 1930-х гг.

Объем этого издания, как было указано в заключительных строках проекта, предполагался внушительный: 4-5 томов по 50 авторских листов на каждый том [ЛЭ, л. 12]. Можно сейчас только предполагать, каким бы интересным, неоднозначным и оригинальным могла получиться эта энциклопедия, если бы ее издание было осуществлено. По сути дела мы держим в руках проект первого лингвистического справочника, отражающего научные интересы и идеологическую борьбу в эпоху расцвета марровского учения о языке, - своеобразный исторический памятник философии, теории и социологии филологической науки $1920-1930-$-х гг.

Описанный нами частный эпизод из истории лингвистики важен и в другом отношении: обнародование подобного документа показывает не только общую тенденцию в науковедении тех лет, но и приоткрывает личные судьбы известных ученых, находившихся под определенным влиянием идеологии. Без знания этих фактов невозможно написать более или менее полную и объективную историю отечественного языкознания XX века.

(C) Никитин О.В.

Дата поступления: 23.07.2018

Дата приема в печать: 26. 07.2018 


\section{СОКРАЩЕНИЯ}

Архив РАН - Архив Российской академии наук (Москва).

ЛЭ - Лингвистическая энциклопедия / Составлено Р.О. Шор. - Машинопись 12 лл. с незначительными авторскими вставками. Хранится в личном фонде Р.О. Шор (находится в состоянии обработки и комплектования) в Архиве РАН.

\section{БИБЛИОГРАФИЧЕСКИЙ СПИСОК}

1. Алпатов В.М. Волошинов, Бахтин и лингвистика. М.: Языки славянской культуры, 2005.

2. Алпатов В.М. Розалия Осиповна Шор // Вопросы языкознания. 2009. nо 5. С. 114-131.

3. Алпатов В.М. Языковеды, востоковеды, историки. М.: Языки славянских культур, 2012.

4. Ашнин Ф.Д., Алпатов В.М., Насилов Д.М. Репрессированная тюркология. М.: «Восточная литература» РАН, 2002.

5. Дурново Н.Н. Грамматический словарь: Грамматические и лингвистические термины / Под ред. О.В. Никитина; Сост., вступит. ст., послесл. и прим. О.В. Никитина. М.: Флинта: Наука, 2001.

6. Никитин О.В. Московская диалектологическая комиссия в воспоминаниях Д.Н. Ушакова, Н.Н. Дурново и А.М. Селищева (неизвестные страницы истории Московской лингвистической школы) // Вопросы языкознания. 2002. по 1. С. 91-102.

7. Никитин О.В. Афанасий Матвеевич Селищев: Очерк жизни и деятельности // Селищев А.М. Труды по русскому языку. Т. 1: Язык и общество / Сост. Б.А. Успенский, О.В. Никитин. М.: Языки славянской культуры, 2003. С. 10-21.

8. Никитин О.В. Забытые страницы русской лексикографии 1920-х гг. (предыстория «Ушаковского словаря») // Русский язык в научном освещении. 2004. no 1 (7). С. 195-228.

9. Никитин О.В. Судьба академических лексикографических проектов 1920-х гг. // Актуальные вопросы исторической лексикографии и лексикологии: Материалы Всероссийской Академической школы-семинара / Отв. ред. С.Св. Волков, О.А. Старовойтова. СПб.: Наука, 2005. С. $30-47$.

10. Никитин О.В. Языковая политика 1930-х гг. и «Ушаковский словарь» // Микроязыки. Языки. Интеръязыки: Сборник в честь ординарного профессора Александра Дмитриевича Дуличенко / Под ред. А. Кюннапа, В. Лефельдта, С.Н. Кузнецова. Tartu: Tartu University Press, 2006. C. 459-474.

11. Никитин О.В. Жизнь и труды Александра Матвеевича Пешковского в свете научной полемики его времени // Пешковский А.М. Лингвистика. Поэтика. Стилистика: Избранные труды: Учебное пособие / Сост. и науч. редактор О.В. Никитин. М.: Высшая школа, 2007. C. $14-58$.

12. Никитин O.B. Очерки по истории русской лексикографии первой половины $\mathrm{XX}$ века (толковые словари): монография. Славянск-на-Кубани: Издательский центр филиала КубГУ в г. Славянске-на-Кубани, 2012. 232 с.

13. Никитин О.В. Отечественная лексикография в 1930-е гг.: борьба идей и идеологий (из истории создания и обсуждения «Толкового словаря русского языка» под редакцией Д.Н. Ушакова) // Мир русского слова. 2016. по 3. С. 27-40.

14. Памяти Афанасия Матвеевича Селищева: Сборник статей и документов / Отв. ред. В.И. Макаров. Елец: ЕГУ им. И.А. Бунина, 2003.

15. Памяти Афанасия Матвеевича Селищева: Сборник статей и документов / Отв. ред. В.И. Макаров. Изд. 2-е, испр. и доп. Елец: ЕГУ им. И.А. Бунина, 2005.

16. Поливанов Е.Д. Избранные работы: Труды по восточному и общему языкознанию. М.: Наука, 1991.

17. Робинсон М.А. Судьбы академической элиты: Отечественное славяноведение (1917 начало 1930-х годов) / Отв. ред. Л.Е. Горизонтов. М.: Индрик, 2004. 


\title{
"LINGUISTIC ENCYCLOPEDIA" - AN UNKNOWN LEXICOGRAPHICAL PROJECT OF THE 1930S
}

\author{
Oleg V. Nikitin \\ Moscow Region State University \\ Vera Voloshina str., 24, Mytishchi, Moscow region, Russia, 141014
}

\begin{abstract}
The article analyses the project of "Linguistic encyclopedia" of the 1930s. The concept of publication was designed by the famous historian and theoretician of linguistics R. O. Shor in the form of expanded memorandum to the Research Institute of linguistics. The idea of creating a "Linguistic encyclopedia" included in the context of scientific discussions, social and political situation of the 19201930s and those tasks which arose before the Soviet scientists on the language construction, technique of learning languages of the southern regions of the country, the development of the General theory and methodology of linguistics. The author emphasizes obvious ideological nature of many statements, which testifies to the struggle of different directions in linguistics and the growing pressure of marrism. For the first time the original text of this project from the collection of the Archives of Russian Academy of Sciences is presented and commented. The paper solves an obscure problem in the history of linguistics and contributes to the objective understanding of the complex processes of linguistic sociology of science in the period of adaptation to the new conditions (discussions, repression of traditional comparative studies, fighting with "polivanovchshina", etc.).
\end{abstract}

Key words: history and theory of linguistics, linguistic discussion, marrism, language situation, lexicography

\section{REFERENCES}

1. Alpatov, V.M. (2005). Voloshinov, Bakhtin and linguistics. Moscow: Languages of Slavic culture. (In Russ.).

2. Alpatov, V.M. (2009). Rosalia Osipovna Shor. Voprosy yazykoznaniya (=Problems on linguistics), 5, 114-131.

3. Alpatov, V.M. (2012). Linguists, orientalists, historians. Moscow: Languages of Slavic cultures. (In Russ.).

4. Ashnin, F.D., Alpatov, V.M. \& Nasilov, D.M. (2002). Repressed Turkology. Moscow: "Eastern literature" of Russian academy of sciences. (In Russ.).

5. Durnovo, N.N. (2001). Grammatical dictionary: Grammatical and linguistic terms, edited by O.V. Nikitin; Comp., comm. by O.V. Nikitin. Moscow: Flinta: Nauka. (In Russ.).

6. Nikitin, O.V. (2002). Moscow dialectological commission in the memoirs by D.N. Ushakov, N.N. Durnovo and A.M. Selishchev (unknown pages of history of the Moscow linguistic school). Voprosy yazykoznaniya (=Problems on linguistics), 1, 91-102. (In Russ.).

7. Nikitin, O.V. (2003). Afanasiy Matveevich Selishchev: Sketch of life and work. In: Selishchev, A.M. Works on the Russian language. Vol. 1. Language and society. Comp. by B.A. Uspensky, O.V. Nikitin. Moscow: Languages of Slavic culture. pp. 10-21. (In Russ.).

8. Nikitin, O.V. (2004). Forgotten pages of Russian lexicography of the 1920s (The prehistory of "The Ushakov dictionary"). Russkij yazyk v nauchnom osvechshenii (=Russian language in scientific coverage), 1(7), 195-228. (In Russ.).

9. Nikitin, O.V. (2005). The fate of academic lexicographical projects of the 1920s. In: Actual issues of historical lexicography and lexicology: Materials of the all-Russian Academic schoolseminar. Sankt-Peterburg: Nauka. pp. 30 - 47. (In Russ.). 
10. Nikitin, O.V. (2006). Language policy of the 1930s and "The Ushakov dictionary". In: Microlanguages. Languages. Interlanguages: a Collection in honor of Professor Alexander Dmitrievich Dulichenko. Tartu: Tartu University Press. pp. 459-474. (In Russ.).

11. Nikitin, O.V. (2007). The Life and works by Alexander M. Peshkovsky in the light of the scientific controversy of his time In: Peshkovsky, A.M. Linguistics. Poetics. Style: Selected works: textbook. Comp. and scientific editor O.V. Nikitin. Moscow: Higher school. pp. 14-58. (In Russ.).

12. Nikitin, O.V. (2012). Essays on the history of Russian lexicography of the first half of the XX century (explanatory dictionaries): monograph. Slavyansk-on-Kuban: Publishing center of the branch of Kuban State University in Slavyansk-on-Kuban. (In Russ.).

13. Nikitin, O.V. (2016). Russian lexicography in the 1930s: the struggle of ideas and ideologies (from the history of the creation and discussion of "The Explanatory dictionary of the Russian language" edited by D.N. Ushakov). Mir russkogo slova (=The World of Russian word), 3, 27-40. (In Russ.).

14. In Memory to Afanasij Matveevich Selishchev: a Collection of articles and documents. Elets: I.A. Bunin Elets State University. (In Russ.).

15. In Memory to Afanasij Matveevich Selishchev: a Collection of articles and documents. Elets: I.A. Bunin Elets State University. (In Russ.).

16. Polivanov, E.D. (1991). Selected works: Writings on Oriental and General linguistics. Moscow: Nauka. (In Russ.).

17. Robinson, M.A. (2004). The fate of the academic elite: Russian Slavic studies (1917 - the beginning of 1930-ies). Ed. by L.E. Gorizontov. Moscow: Indrik. (In Russ.).

\section{Для цитирования:}

Никитин O.B. «Лингвистическая энциклопедия» - неизвестный лексикографический проект 1930-х гг. // Вестник Российского университета дружбы народов. Серия: Теория языка. Семиотика. Семантика, 2018. Т. 9. № 3. С. 612-624. doi: 10.22363/2313-2299-2018-9-3612-624.

\section{For citation:}

Nikitin, O.V. (2018). "Linguistic encyclopedia" - an unknown lexicographical project of the 1930s. RUDN Journal of Language Studies, Semiotics and Semantics, 9(3), 612 -624. doi: 10.22363/23132299-2018-9-3-612-624.

\section{Сведения об авторе:}

Никитин Олег Викторович, доктор филологических наук, профессор кафедры истории русского языка и общего языкознания Московского государственного областного университета; научные интересы: история языкознания, лексикография, философия и история языка, общая филология, семиотика; e-mail: olnikitin@yandex.ru

\section{Information about the author:}

Oleg V. Nikitin, Doctor of Philology, Professor of the Department of history of the Russian language and General linguistics at the Moscow Region State University; research interests: history of linguistics, lexicography, philosophy and history of language, General Philology, semiotics; e-mail: olnikitin@yandex.ru 